\title{
The Social Rights and Responsibilities of Pregnant Women: An Application of Parsons's Sick Role Model*
}

\author{
SHEILA TAYLOR MYERS \\ HAROLD G. GRASMICK
}

\begin{abstract}
A study sought to identify the role expectations ascribed to pregnancy, and to examine whether such expectations differed across categories of socioeconomic status, age, race, and gender. In particular, the adequacy of Parsons's model of the sick role for describing social expectations for pregnant women was analyzed. For each of the four components of Parsons's sick role, items were developed for a questionnaire administered to a sample of 329 adults in a metropolitan community. The results indicate that for the vast majority of the respondents, the behavior expected of pregnant women is similar to Parsons's sick role. A factor analysis of item responses, however, reveals that they are not unidimensional. Furthermore, significant variation occurred across categories of socioeconomic status, gender, race, and age in the extent to which respondents ascribed the four components of the sick role to pregnancy. Policy implications of these findings are discussed.
\end{abstract}

\section{INTRODUCTION}

Within the medical profession in the United States, a firmly entrenched norm is that women should obtain health care during pregnancy as early as the first trimester. This norm is being exported to third world countries as the most effective way to reduce costly illness and death linked to pregnancy and birth. Yet even in the face of such clear-cut directives, $24 \%$ of the women delivering live births in the United States in 1986 did not receive prenatal care during the first trimester of their pregnancies (Children's

\footnotetext{
The Journal of Applied Behavioral Science

Volume 26, Number 2, pages 157-172.

Copyright $($ ) 1990 by NTL Institute.

All rights of reproduction in any form reserved.

ISSN: 0021-8863
}

Defense Fund, 1987). As a result, problems persist with low birth weight and neonatal morbidity and mortality, along with health risks for pregnant women. This leads not only to personal tragedies for the people involved, but also to tremendous medical costs for providing neonatal intensive care facilities for babies with low birth weights.

*Data for this research were collected as part of the annual Oklahoma City Survey, directed by Harold G. Grasmick and Robert J. Bursik and funded by the College of Arts and Sciences, University of Oklahoma. The authors thank Timothy M. Taylor for ideas used in questions of no-fault expectations for pregnancy.

Sheila Taylor Myers is an assistant professor in the School of Nursing and Harold G. Grasmick is a professor in the Department of Sociology at the University of Oklahoma, Norman, OK 73019. 
The women least likely to receive adequate care during pregnancy are those who have relatively less education and lower income, belong to minorities, are single, are not in the labor force, and already have had one or two children. There is also a curvilinear relationship with age. Teenagers and women over 35 are less likely to receive adequate care than women in the middle of the range of child-bearing years (Ryan, Sweeney, \& Solola, 1980) (for a recent overview of the literature on this problem, see St. John \& Winston, 1989).

Much concern has been expressed about the barriers to adequate health care during pregnancy (Brown, 1988; Collver \& Have, 1974; Joyce, Diffenbacher, Greene, \& Sorokin, 1983; Kaliszer \& Kidd, 1981; Polland, Ager, \& Olson, 1987; Watkins, 1978). These barriers include geographical distribution of services, prohibitive cost, lack of transportation, inadequate capacity of the health care system, and the absence of support systems for some pregnant women.

One possible barrier that so far has been neglected is that of the role expectations that society, or some segments of society, hold for pregnant women. Roles are a key element in a social system, providing a blueprint for behavior and expectations - from the point of view of the collectivity-concerning what an incumbent of a particular status should do. The role expectations society holds of pregnant women derive from and are indicative of the status held by pregnant women within the society. Kitzinger maintains that “... in any society, the way a woman gives birth, and the kind of care given her, point as sharply as an arrowhead to the key values in the culture" (1985, p. 115). Thus, an understanding of the expectations society holds for pregnant women and the social context in which these occur might contribute to an understanding of why problems concerning adequate prenatal care persist.

Pregnancy is as much a social role as it is a biological process. That role consists of expectations in the social environment as to how pregnant women should behave. A growing body of literature, derived from a variety of perspectives, focuses on the role of pregnancy. For example, pregnancy has been conceptualized as a transition period in which a woman moves from one role into another (Rubin, 1967a, b; Williams, Joy, Travis, Gotowiec, Blum-Steele, Aiken, Painter, \& Davidson, 1987). Others have used the idea of status passage (Bromberg, 1981; Hart, 1977; van Gennep, 1960) to describe the transition. These frameworks highlight change and focus on the process of status acquisition from the viewpoint of the pregnant woman. Other authors (Arms, 1975; Oakley, 1980, 1984; Romalis, 1981; Rothman, 1982; Shaw, 1974) have documented the experiences of pregnant women within the health care system, focusing on political control and economic power. Although all of these perspectives offer important insights, our concern is with the expectations that exist in the larger society, external to women's own experiences of role transition and before they enter the health care delivery system.

McKinlay (1972) regards the state of pregnancy in society as intriguing simply because the role is so ill-defined. Pregnancy may be viewed as a normal developmental state whereby a pregnant woman is expected to continue functioning capably with few, if any, accommodations to her pregnancy. On the other hand, pregnancy may be considered an illness state whereby the pregnant woman is expected to conform to the sick role, one component of which is to seek medical care and to cooperate with the care giver. It is unclear which of these general sets of expectations is predominant among the public, and it is possible that different segments of society have different role expectations for pregnant women. Especially with the fairly recent advent of prepared childbirth and the view of childbirth as a normal physiological function, being pregnant may be considered at odds with the implication of being sick and in need of medical care.

The research reported in this article was done in an attempt to identify the role expectations 
people ascribe to pregnancy, and to explore the possibility that such expectations are not the same across categories of socioeconomic status, age, gender, and race. In particular, we analyzed the adequacy of Parsons's (1951) model of the sick role as a way to describe the social expectations people have for women who are pregnant. It is not our contention that pregnancy must be viewed as a sick role in order for pregnant women to obtain adequate medical care. We do suggest, however, that the reluctance of some people to ascribe the sick role to pregnancy, given the current structure of health care delivery to pregnant women, possibly creates a social barrier that should be addressed in any effort to provide adequate health care for pregnant women.

\section{OVERVIEW}

\section{Pregnancy as a Sick Role: An Application of Parsons's Model}

The description of the sick role by Parsons (1951) has been an analytical tool for examining socially appropriate, or normative, sickness behavior in our society. Parsons's original formulation was limited to norms governing temporary, acute physical illness. The sick role is framed by both rights and responsibilities for the one labeled sick and for society in general. The two rights are as follows:

1. The sick person is exempt from performance of normal social role obligations.

2. The sick person is exempt from being held responsible for being sick.

The two responsibilities imposed on a sick person are as follows.

1. The sick person should be motivated to get well quickly.

2. The sick person should seek technically competent help and then cooperate with those experts.

According to Parsons, these rights and responsibilities coalesce into a unidimensional set of expectations - that is, the "sick role"-that society has of people when they are sick. The sick role, according to Parsons (1951, 1964), constitutes deviance from the norm of health. Defined in terms of incapacity for task performance, which warrants social control, the sick role can be viewed from a cost/benefit perspective. Benefits in the form of relief from social responsibility and privileged dependency are gained at the cost of social restriction, lowered productivity, and consequent lowered status.

During the past three decades, Parsons's model has been extended beyond temporary, acute physical illness to situations of chronic illness (Kassebaum \& Baumann, 1965) and psychiatric illness (Blackwell 1967), and even to pregnancy (Rosengren, 1961, 1962a, b). In general, Parsons's conceptualization is regarded by many as a useful starting place for the analysis of any kind of behavior related to sickness (Arluke, Kennedy, \& Kessler, 1979; Mechanic, 1962). By 1979 , Arluke et al. were able to identify fifty studies using Parsons's sick role conceptualization.

Among the various criticisms of Parsons's model and the research focused upon it, two were most central to our research. First, the model should recognize the possibility of variation within a society in the extent to which individuals with a particular "illness" are expected to behave in accord with the norms of the sick role (McKinlay, 1972; Twaddle, 1969). Among the upper class, for example, the expectations held for people who are alcoholics might be much different than among the lower class. In other words, in some segments of society the sick role, with its rights and responsibilities, might be considered the appropriate behavior for an alcoholic, whereas in other segments of society an alcoholic might not have these rights and responsibilities. The same argument could apply to pregnancy.

The second relevant criticism in the literature focuses on confusion between the self-identity and behavior of sick people on the one hand, and the social expectations that society has for sick people on the other (Arluke et al., 1979; Twaddle 
\& Hessler, 1977). From their review of research, Arluke et al. (1979) conclude that the vast majority of studies have concentrated on the willingness of individuals to adopt the sick role, rather than on the expectations others hold for people who are sick. In the study of the sick role, in contrast to Parsons's original formulation, the usual subject has been the patient. This focus on the patient, rather than on society's expectations for the patient, has characterized the study of pregnancy from the sick role perspective. Following a series of studies reported in the early 1960s, Rosengren (1961, 1962a, b) described the results of interviews with pregnant women concerning the extent to which they regarded themselves as sick. But the question of whether pregnant women see themselves as sick is different from the question of whether society, or some segments of society, grants pregnant women the two rights in Parsons's model and expects them to conform to the two responsibilities.

Within Parsons's framework, it is unclear what rights and responsibilities the general public ascribes to the role of being pregnant and whether these rights and responsibilities are invariant across social groupings. McKinlay (1972) insists that the normal state of pregnancy is in significant ways different from "ordinary" illness and cannot be viewed in terms of Parsons's concept of sick role rights and responsibilities. Role expectations attached to the condition of being pregnant appear to be in a state of limbo between illness and normality in the United States. Physiologically, pregnancy is a normal developmental adaptation. Historically, over the past 150 years, women have described their own pregnancies in terms of sickness (Arpad, 1984; Ehrenreich \& English, 1979; Leavitt, 1986). Medically, physicians have described pregnancy in terms of pathology (DeLee, 1920) and diagnostic etiology (Hern, 1975), securing the management and control of pregnancy within the health care system.

Regardless of what critics of the health care system might think should be, the fact remains that, for the most part, the health care facilities in which pregnant women can receive care are the same facilities that treat illnesses, and the care givers much resemble those who provide care for the temporarily and chronically ill. Regardless of the advantages or disadvantages of such an institutional arrangement, the structure of providing care to pregnant women is closely tied to the institutions that treat illness. It is within this context that Parsons's sick role model might be a potentially useful heuristic device. Until or unless the institutional arrangements change, it would seem that the extent to which people's expectations for pregnant women conform to the components of Parsons's sick role is an important issue for any effort to provide adequate care for pregnant women. The goal of our research is to begin to answer this question.

In our study we first identified a set of specific expectations concerning the role of pregnant women, which are not necessarily widely shared, that would correspond to the general rights and responsibilities in Parsons's description of the sick role. Then, using the sample survey method, we judged the prevalence of these expectations in our study sample and determined if they coalesce into a unidimensional sick role associated with pregnancy. Finally, we examined whether these expectations vary across categories of socioeconomic status, age, gender, and race.

\section{Sick Role Components and Pregnancy}

For each of the two rights and two responsibilities in Parsons's description of the sick role, we have attempted to identify specific expectations concerning women who are pregnant. We do not, however, maintain that these expectations are widely shared in society; rather, their prevalence is an empirical matter we assess.

The first "right" of sick people, according to Parsons, is the right to be excused from certain social role responsibilities. If being pregnant qualifies one for the sick role, then we expect 
widespread agreement that pregnant women should be exempt from at least some other normal duties. To tap this dimension of the sick role as it relates to pregnancy, we developed the following questionnaire items to be answered in a Likert-type agree/disagree format. We call this the Excuse component of the sick role.

When a woman is pregnant, she should not be expected to carry all the responsibilities she carried before she became pregnant.

In general, the husband or family of a pregnant woman should not expect her to do as much for them as she did before she was pregnant.

Women who are pregnant deserve extra protection and care.

The second right presented in Parsons's model is the right not to be held responsible for being sick. This component of the sick role is somewhat difficult to link to pregnancy since, in most cases, women usually are ascribed the responsibility of fertility control. We do, however, see a parallel to the sick role in terms of employers' policies concerning pregnancy and illness. Becoming sick is "normal" in the sense that sooner or later it will happen to most people. Becoming pregnant also is "normal" in that it will happen to many young women in the labor force. Are there expectations, therefore, that pregnant women have the same rights as sick people in terms of their role in the labor force, or are the protections that society is willing to extend to sick people not extended to pregnant women? To tap this dimension of the sick role, which we call No Fault, we developed the following questionnaire items. Agreement with these items would indicate that, at least in the realm of the work force, people grant pregnant women the "no-fault" rights they grant sick people.

Maternity leave should be treated like sick leave since it is not the woman's fault that she needs to be off work.

Companies should have policies that allow women to take maternity leave without a dock in pay.

A working woman should not lose seniority for the time she takes off on maternity leave any more than for sick leave.

The first of the two "responsibilities" presented in Parsons's model is the expectation that a sick person should want to get well and not linger in the sick role. The issue for pregnancy seems to be whether the person is expected to relish the state of pregnancy or to look forward to being over it so that normal responsibilities can be resumed. We call this component of the sick role Get Well and have developed the following questionnaire items for it. Agreement with the items would suggest that the respondent expects a pregnant woman to be eager for the birth to occur so that she can return to her normal roles.

While a pregnant woman might be given some extra privileges and considerations, after the baby comes she should expect to return to her family responsibilities pretty quickly.

Even while she is pregnant, a woman should be looking forward to getting back to her normal responsibilities when the pregnancy is over.

Toward the end of her pregnancy, a woman should be eager for it to be over so that she can get back to her normal routine.

Finally, sick people have the responsibility of seeking medical care and cooperating with the care giver. We call this component of the sick role Care and developed the following questionnaire items to measure whether respondents believe it applies to pregnancy. Agreement with the items would indicate the presence of the expectation that pregnant women should seek medical care.

When a woman is pregnant she should get expert care for her pregnancy.

As soon as a woman thinks she is pregnant she 
should immediately go see a doctor rather than waiting until she thinks she needs special care.

When a woman is pregnant she should see a doctor or go to a clinic on a regular basis even if she does not feel like she needs medical treatment.

Again, we stress that we are not assuming a priori that the public generally grants these rights to or imposes these responsibilities on pregnant women. Nor are we assuming that these expectations coalesce into a single factor since people who hold some of these expectations might not necessarily hold others. These are issues our research addressed.

\section{Pregnancy, Sick Role and Social Context}

In this section, we consider the possibility that the extent to which people hold sick role expectations for pregnant women might vary across categories of gender, socioeconomic status, race, and age. In the absence of any previous direct evidence, all of our hypotheses should be viewed as tentative.

Women in our society live longer than men and have lower mortality rates for most causes of death. Nathanson (1975), however, has summarized statistical surveys that indicate that women in the United States report more physical and mental illness than men and utilize health services at much higher rates. In her attempt to explain these patterns, Nathanson suggests that women might be more likely than men to view illness behavior, or the sick role, as acceptable role behavior. Thus, one might predict that women would be more likely than men to consider the sick role appropriate for a woman who is pregnant. Furthermore, men might often find it in their own "self-interest" not to grant their pregnant wives exemption from normal social role obligations, since many of the household obligations would then be transferred to the husbands. Overall, therefore, it seems possible that women would be more likely than men to consider the sick role expectations appropriate for pregnancy.

Socioeconomic status and race also might influence the tendency to ascribe the sick role to pregnancy. Given the cost of health care, lower class norms might be more likely to discourage the sick role. In addition, financial constraints might make it more difficult for the lower class and minorities to grant pregnant women exemptions from other role responsibilities, such as employment. Thus, one might predict that persons of lower socioeconomic status and minorities would be less likely to view the sick role as the appropriate response to pregnancy.

Age might also be an important determinant of the extent to which people hold sick role expectations for pregnant women. Historically, the views of the medical community concerning pregnancy have changed, and these changes might have produced generational differences in the expectations people have for pregnant women. Specifically, recent years have been marked by a trend toward treating childbirth as "natural," a trend that has involved fathers as well as mothers. Consequently, younger people, confronting this set of norms, might be less likely to ascribe sick role expectations to pregnancy. Conversely, many elderly experienced pregnancy, as either mothers or fathers, at a time when childbirth often occurred in the home with relatively little professional medical attention. As a result, the oldest respondents in a survey, like the youngest, might be inclined to reject the sick role expectations for pregnant women. Many middle-aged people, on the other hand, experienced pregnancy when the recommended hospital stay for delivery was five to seven days, followed by fourteen days of inactivity at home. Thus, because of their different generational experiences, middle-aged people might strongly endorse the sick role norms for pregnant women.

Based on the arguments above, we expected the following categories of people to most strongly advocate the sick role for pregnant women: women, individuals of high socioeco- 
nomic status, whites, and middle-aged people. In addition, we considered the possibility of interaction effects. For example, we predicted that women would be more likely than men to view the sick role as appropriate for pregnant women, but considered it possible that the magnitude of the effect of gender varies across categories of age. For example, because of the recent emphasis on bringing fathers actively into the birthing process, we suspected that the effect of gender might be less pronounced for younger persons than for older ones. We consider this and other possible interaction effects in our analysis.

\section{METHODS}

The data were collected as part of the 1985 Oklahoma City Survey. This is an annual community survey covering a variety of topics in any one year, which has been conducted by the Department of Sociology at the University of Oklahoma since 1979. The sample of 329 adult residents of Oklahoma City was randomly selected from the R. L. Polk Directory, which provides the most complete listing of residents available, and does not differ significantly from the 1980 Census figures for the distributions of gender, race, age, and education. Refusals were replaced by resampling until the target sample size was achieved. Interviews were conducted face to face by trained interviewers who read the questions and response options to respondents and then recorded their answers.

The sample was limited to a particular region of the country and to an urban area. Thus, we must be cautious in generalizing our findings. In future research, it might be useful to explore the possibility of regional differences or urbanrural differences in the extent to which expectations held for pregnant women correspond to the sick role. Our own sample, however, did not permit consideration of these issues.

In the analysis that follows, gender and race are treated as dummy variables. For the variable Woman, women (45.6\%) are coded 1, and men coded 0 . For the variable White, whites $(83.0 \%)$ are coded 1 , and all nonwhites coded 0 (the number of nonwhites in the sample was too small to distinguish between various racial/ethnic groups).

The mean age of the sample was 45.0 , with a standard deviation of 17.3 years. Because, however, we predicted a curvilinear relationship between age and endorsement of the sick role for pregnancy, we collapsed age into three categories-18-34, 35-49, and 50 and older-and then formed two dummy variables from these categories. The variable Young separates respondents who were under 35 from everyone else. The variable Old separates respondents who were 50 and older from everyone else. Middle-aged respondents (35-49) represented the residual category in the regressions reported. We expected the coefficients for both Young and Old to be negative, meaning that both of these groups were predicted to be less likely than middle-aged respondents to view the sick role as appropriate for a pregnant woman.

Socioeconomic status (SES) is a composite of years of education, family income, and the occupational prestige of the head of household. For those respondents who did not report their family income $(n=25$, or $7.6 \%)$, regression procedures were used to estimate the income as a function of education and occupational prestige. The mean family income for the sample was $\$ 31,600$, and the mean respondent education was 13.5 years. All three of the components of SES were standardized before they were summed to form the scale.

\section{ANALYSIS}

Table 1 reports the univariate distributions of the 12 items designed to measure whether respondents viewed the sick role as appropriate for pregnant women. Each item is in the Likert format with response options of "strongly agree," "agree somewhat," "disagree somewhat," and "strongly disagree." 
Table 1

Questionnaire Items, Frequencies, and Factor Analysis for Sick Role Components $(N=329)$

\begin{tabular}{|c|c|c|c|c|c|c|c|c|}
\hline \multirow[b]{3}{*}{ Item } & \multicolumn{4}{|c|}{ Frequencies } & & & & \\
\hline & \multirow{2}{*}{$\begin{array}{l}\text { Strongly } \\
\text { Agree }\end{array}$} & \multirow{2}{*}{$\begin{array}{c}\text { Agree } \\
\text { Somewhat }\end{array}$} & \multirow{2}{*}{$\begin{array}{l}\text { Disagree } \\
\text { Somewhat }\end{array}$} & \multirow{2}{*}{$\begin{array}{l}\text { Strongly } \\
\text { Disagree }\end{array}$} & \multicolumn{4}{|c|}{ Factor Loadings } \\
\hline & & & & & $I$ & II & III & $I V$ \\
\hline \multicolumn{9}{|l|}{ Excuse } \\
\hline $\begin{array}{l}\text { When a woman is preganant, she should } \\
\text { not be expected to carry all the responsi- } \\
\text { bilities she carried before she became } \\
\text { pregnant. }\end{array}$ & $31.3 \%$ & $42.2 \%$ & $17.0 \%$ & $9.4 \%$ & -.063 & +.812 & +.046 & +.032 \\
\hline $\begin{array}{l}\text { In general, the husband or family of a } \\
\text { pregnant woman should not expect her to } \\
\text { do as much for them as she did before she } \\
\text { was pregnant. }\end{array}$ & $41.6 \%$ & $44.4 \%$ & $11.2 \%$ & $2.7 \%$ & +.079 & +.863 & +.100 & +.001 \\
\hline $\begin{array}{l}\text { Women who are pregnant deserve extra } \\
\text { protection and care. }\end{array}$ & $59.6 \%$ & $32.8 \%$ & $6.7 \%$ & $0.9 \%$ & +.068 & +.755 & +.149 & -.147 \\
\hline \multicolumn{9}{|l|}{ No Fault } \\
\hline $\begin{array}{l}\text { Maternity leave should be treated like sick } \\
\text { leave since it is not the woman's fault that } \\
\text { she needs to be off work. }\end{array}$ & $45.6 \%$ & $29.2 \%$ & $18.2 \%$ & $7.0 \%$ & +.009 & +.178 & +.810 & +.004 \\
\hline $\begin{array}{l}\text { Companies should have policies that allow } \\
\text { women to take maternity leave without a } \\
\text { dock in pay. }\end{array}$ & $48.0 \%$ & $27.0 \%$ & $16.1 \%$ & $8.8 \%$ & -.001 & +.022 & +.845 & +.070 \\
\hline $\begin{array}{l}\text { A working woman should not lose seniority } \\
\text { for the time she takes off on maternity leave } \\
\text { any more than for sick leave. }\end{array}$ & $72.6 \%$ & $18.8 \%$ & $5.8 \%$ & $2.7 \%$ & +.217 & +.104 & +.719 & +.131 \\
\hline \multicolumn{9}{|l|}{ 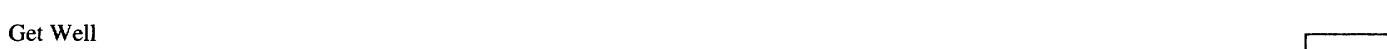 } \\
\hline $\begin{array}{l}\text { While a pregnant woman might be given } \\
\text { some extra privileges and considerations, } \\
\text { after the baby comes she should expect to } \\
\text { return to her family responsibilities pretty } \\
\text { quickly. }\end{array}$ & $32.5 \%$ & $50.1 \%$ & $15.2 \%$ & $2.1 \%$ & +.165 & -.093 & +.034 & +.746 \\
\hline $\begin{array}{l}\text { Even while she is pregnant, a woman } \\
\text { should be looking forward to getting back } \\
\text { to her normal responsibilities when the } \\
\text { pregnancy is over. }\end{array}$ & $37.1 \%$ & $46.5 \%$ & $13.4 \%$ & $2.0 \%$ & +.129 & +.007 & +.078 & +.840 \\
\hline $\begin{array}{l}\text { Toward the end of her pregnancy, a woman } \\
\text { should be eager for it to be over so that she } \\
\text { can get back to her normal routine. }\end{array}$ & $30.1 \%$ & $41.6 \%$ & $21.6 \%$ & $6.7 \%$ & -.009 & -.015 & +.078 & +.785 \\
\hline \multicolumn{9}{|l|}{ Care } \\
\hline $\begin{array}{l}\text { When a woman is pregnant, she should get } \\
\text { expert care for her pregnancy. }\end{array}$ & $91.8 \%$ & $6.4 \%$ & $1.2 \%$ & $0.6 \%$ & +.711 & +.012 & +.170 & +.104 \\
\hline $\begin{array}{l}\text { As soon as a woman thinks she is pregnant } \\
\text { she should immediately go see a doctor } \\
\text { rather than waiting until she thinks she } \\
\text { needs special care. }\end{array}$ & $80.2 \%$ & $15.5 \%$ & $2.7 \%$ & $0.9 \%$ & +.869 & +.069 & +.007 & +.110 \\
\hline $\begin{array}{l}\text { When a woman is pregnant she should see } \\
\text { a doctor or go to a clinic on a regular basis } \\
\text { even if she does not feel like she needs } \\
\text { medical treatment. }\end{array}$ & $78.7 \%$ & $17.9 \%$ & $2.4 \%$ & $0.9 \%$ & +.869 & -.002 & +.020 & +.065 \\
\hline
\end{tabular}


As can be seen, there is extensive agreement with these items. The percentage who strongly agreed or agreed somewhat ranged from 71.7 for one of the Get Well items to 98.2 for one of the Care items. Overall, the extent of agreement is highest for the Care items and lowest for the No Fault items. But even for the No Fault items, about three-fourths of the sample agreed either strongly or somewhat that these are appropriate rights for pregnant women.

Having established that in our sample these various sick role expectations were widely held, we considered whether they coalesced into a unidimensional set of expectations. In other words, we asked whether the people who most strongly endorsed one of these expectations were the same people who most strongly endorsed the others. In previous applications of the sick role model to specific situations, unidimensionality was an untested assumption. We addressed this issue with factor analysis, and the results of the principal components analysis clearly revealed the presence of four significant factors. The eigenvalues of the first four factors were $2.42,2.30,1.66$, and 1.35 , whereas the eigenvalue of the fifth factor was only 0.85 . A varimax rotation yielded the factor loadings reported in Table 1.

The patterns of the factor loadings indicate that each of the four rights and responsibilities constitutes a separate factor. In other words, for example, those respondents who most strongly endorsed the right of pregnant women to be excused from normal roles were not necessarily the same respondents who most strongly held the expectation that pregnant women should seek care. Because four factors are necessary to reproduce the correlations among the expectations, it is inappropriate to create a single scale of sick role expectations for pregnant women. Instead, four scales were created - one for each of the rights and responsibilities. In each case, the $\mathrm{z}$-score transformations of the relevant items were summed. The reliability estimates, as measured by Cronbach's alpha, for these scales are
.75 (Excuse), .73 (No Fault), .72 (Get Well) and .77 (Care). Thus, all four scales have a high level of internal consistency and meet acceptable standards for reliability.

The correlations among the four scales, with two-tailed significance tests, are reported in Table 2.

Table 2

Bivariate Correlations Among Sick Role Component Scales $(N=329)$

\begin{tabular}{|c|c|c|c|}
\hline & Excuse & No Fault & Get Well \\
\hline No Fault & $\begin{array}{l}.202 \\
(p .<001)\end{array}$ & & \\
\hline Get Well & $\begin{array}{l}-.106 \\
(p=.054)\end{array}$ & $\begin{array}{l}.141 \\
(p=.010)\end{array}$ & \\
\hline Care & $\begin{array}{l}-.015 \\
(p=.793)\end{array}$ & $\begin{array}{l}.071 \\
(p=.201)\end{array}$ & $\begin{array}{c}+.165 \\
(p=.003)\end{array}$ \\
\hline
\end{tabular}

The absence of strong positive correlations among the scales provides further evidence that expectations were not unidimensional. Of the six correlations among the four scales, the largest positive one is .212 (Excuse and No Fault), followed by .165 (Care and Get Well), .141 (No Fault and Get Well), and .071 (Care and No Fault). Two correlations, in fact, are negative (.106 between Get Well and Excuse, and -.015 between Excuse and Care).

The finding that sick role expectations for pregnant women were not unidimensional complicates the test of the general hypothesis that the strength of these expectations would vary across categories of age, gender, SES, and race. It thus became necessary to consider the effects of these independent variables on each of the four sick role components. We begin in Table 3 with the bivariate correlations, and report the multivariate analysis in Table 4. Throughout the analysis, we used conservative two-tailed tests and the conventional .05 level to assess statistical significance. In this section, we simply describe the findings, reserving our interpretation of the results for the next section. 
Table 3

Bivariate Correlations of Socio-Demographic Variables with the Four Sick Role Expectations $(N=329)$

\begin{tabular}{lllll}
\hline & Excuse & No Fault & Get Well & Care \\
\hline Woman & -.277 & -.014 & +.280 & +.097 \\
& $(p .<001)$ & $(p=.800)$ & $(p .<001)$ & $(p=.080)$ \\
SES & -.098 & -.169 & -.168 & +.150 \\
& $(p=.074)$ & $(p=.002)$ & $(p=.002)$ & $(p=.006)$ \\
White & -.043 & -.043 & +.048 & +.112 \\
& $(p=.436)$ & $(p=.438)$ & $(p=.392)$ & $(p=.042)$ \\
Old & +.042 & -.177 & +.200 & +.064 \\
& $(p=.450)$ & $(p=.002)$ & $(p .<001)$ & $(p=.148)$ \\
Young & +.027 & +.160 & -.227 & -.106 \\
& $(p=.628)$ & $(p=.004)$ & $(p .<001)$ & $(p=.056)$ \\
\hline
\end{tabular}

The rows of Table 3 reveal a complicated pattern of correlations. None of the sociodemographic variables are consistently correlated with all four of the sick role expectations. Women tend to score lower than men on Excuse but higher than men on Get Well. Bivariate gender differences are not significant for Get Well and Care. Socioeconomic status is inversely correlated with No Fault and Get Well, positively correlated with Care, and not significantly related to Excuse. Racial differences appear only for Care, with whites tending to score higher than nonwhites on this expectation. Compared to others, older people were significantly less supportive of the No Fault expectation but more supportive of the Get Well responsibility. Younger people, compared to others, were more committed to the No Fault right, but less committed to the Get Well responsibility.

Table 4 reports the results of multiple regression analyses examining the direct effects of the four independent variables, as well as their interactions. We followed a backwards selection process, eliminating higher order interactions until we arrived at an ordinary least-squares equation containing all main effects and only the significant interactions. Interactions are represented as products. In the equations, age is captured by the two dummy variables Old and
Young. With both of these variables in the equation, Old compares people 50 and older to people 35-49, while Young compares people under 35 to people 35-49. Again, conservative two-tailed tests were used.

In the top panel, with Excuse as the dependent variable, only Woman indicates a significant main effect. The negative sign suggests, somewhat unexpectedly, that women are less likely than men to believe that pregnant women should be excused from normal role responsibilities. The table also reveals a significant interaction effect of Woman and SES. Given the nature of the dummy coding, the insignificant $b$ of -.022 for SES is the effect of SES on Excuse among men. The effect of SES on Excuse for women is this -.022 plus the significant $b$ of -.286 for the Woman x SES interaction term (i.e., -.308). Overall, therefore, the equation suggests that women are less likely than men to believe that pregnant women should be excused from normal role responsibilities; and, among women, those of higher socioeconomic status are even less likely to hold this view than women of lower socioeconomic status.

The second panel of Table 4 contains the results with No Fault as the dependent variable-operationalized as the belief that pregnant women in the labor force are entitled to the 
Table 4

Effects of Socio-Demographic Variables on the Four Sick Role Expectations $(N=329)$.

\begin{tabular}{|c|c|c|c|c|}
\hline Independent Variable & $b$ & Beta & $t$ & $p$ \\
\hline \multicolumn{5}{|l|}{$\begin{array}{l}\text { Dependent: Excuse } \\
\left(\mathrm{R}^{2}=.127, p<.001\right)\end{array}$} \\
\hline Old & .598 & .118 & 1.79 & .074 \\
\hline Young & .329 & .065 & 1.00 & .320 \\
\hline Woman & -1.589 & -.324 & -6.04 & .000 \\
\hline SES & -.022 & -.021 & -.30 & .765 \\
\hline White & -.225 & -.035 & -.64 & .525 \\
\hline Woman $\times$ SES & -.286 & -.174 & -2.54 & .011 \\
\hline \multicolumn{5}{|l|}{$\begin{array}{l}\text { Dependent: No Fault } \\
\left(\mathrm{R}^{2}=.084, p<.001\right)\end{array}$} \\
\hline Old & -.834 & -.168 & -2.45 & .013 \\
\hline Young & .261 & .052 & .78 & .433 \\
\hline Woman & .120 & .025 & .45 & .651 \\
\hline SES & -.272 & -.268 & -4.04 & .000 \\
\hline White & .084 & .013 & .24 & .815 \\
\hline Young $\times$ SES & .322 & .169 & 2.63 & .009 \\
\hline \multicolumn{5}{|l|}{$\begin{array}{l}\text { Dependent: Get Well } \\
\left(\mathrm{R}^{2}=.150, p<.001\right)\end{array}$} \\
\hline Old & .111 & .023 & .35 & .726 \\
\hline Young & -1.021 & -.207 & -3.23 & .002 \\
\hline Woman & 1.118 & .235 & 4.44 & .000 \\
\hline SES & -.173 & -.172 & -3.14 & .002 \\
\hline White & .516 & .082 & 1.52 & .129 \\
\hline \multicolumn{5}{|l|}{$\begin{array}{l}\text { Dependent: Care } \\
\left(\mathrm{R}^{2}=.062, p<.01\right)\end{array}$} \\
\hline Old & .067 & .014 & .20 & .841 \\
\hline Young & -.300 & -.062 & -.92 & .360 \\
\hline Woman & .523 & .112 & 2.00 & .046 \\
\hline SES & -.089 & -.091 & -.73 & .467 \\
\hline White & .196 & .032 & .53 & .599 \\
\hline White $\times$ SES & .188 & .273 & 2.12 & .035 \\
\hline
\end{tabular}

same benefits and protections as sick people. Older respondents, compared to middle-aged respondents, were significantly less likely to endorse this view. The coefficients for SES and the Young $x$ SES interaction term also are significant. Given the dummy coding and the variables in the equation, the significant inverse effect of -.272 for SES is the effect of SES on endorsement of the No Fault expectation for older (50 and older) and middle-aged (35-49) respondents. In other words, in these age categories, as SES increased, support for the No
Fault expectation decreased. The positive $b$ of +.322 for the Young $x$ SES term indicates that the inverse effect of SES on No Fault vanished among younger respondents (i.e., $-.272+.322=$ +.050 ). Overall, therefore, the equation suggests that support for the No Fault expectation was weaker among older respondents, and that SES had an inverse effect among older and middle-aged respondents, but not among younger ones.

The equation for Get Well is reported in the third panel of Table 4. Young people, compared 
to middle-aged respondents, were less strongly committed to the expectation that pregnant women should be eager to return to their normal roles when the pregnancy is completed. Older people did not differ significantly from middleaged respondents. Women more strongly endorsed this responsibility than did men, and commitment to it decreased as socioeconomic status increased. Race did not have a significant direct effect, and there are no significant interaction terms in the Get Well equation.

The bottom panel of Table 4 reports the results for Care, the expectation that pregnant women should seek medical care and cooperate with the care givers. The positive direct effect for Woman indicates that women are more committed than men to this view. The two age variables had no effect. Although SES and race do not have significant main effects, the interaction of race and SES is significant. Given the dummy coding, the $b$ of -.089 for SES, which is not significant, is the effect of SES on Care for nonwhites. Thus, among nonwhites, SES had no effect on the strength of this expectation. Among nonwhites, as SES increased, the strength of this expectation neither increased nor decreased. The effect of SES on Care, however, was significantly different for whites than for nonwhites, as revealed by the significant $b$ for the White $\mathrm{x}$ SES interaction term. The $b$ of +.188 for the interaction term is the difference, so the effect of SES on Care for whites is +.099 (i.e., - $.089+$ .188 ), compared to -.089 for nonwhites. Thus, SES had a positive effect on the strength of endorsement of the Care expectation, but only among whites. Among whites, as SES increased, support for the Care expectation increased.

\section{DISCUSSION}

The intent of this study was to empirically describe the rights people grant to pregnant women and the responsibilities they expect them to meet according to Parsons's model of the sick role. In general, the people in our sample overwhelmingly agreed with the four components of the sick role as appropriate expectations for pregnant women. But those who strongly endorsed one component did not necessarily strongly endorse the others. The four components do not form a unidimensional set of expectations that people have for pregnant women, and we suspect this occurs, at least in part, because the sociodemographic variables leading to endorsement of one component are not always the same as the variables related to endorsement of other components. We now offer some tentative interpretations of our findings in the hope of stimulating future research on pregnancy as a sick role.

Parsons (1951, 1964, 1975) has recognized the consequences of the sick role for the individuals in that role. In contrast to health and capability, the sick role is a deviance role that requires dependency of the occupant. The rights are accompanied by responsibilities, and the incumbent's status and power are reduced. Throughout the analysis we observed gender differences regarding the extent of the endorsement of the various sick role expectations for women. We speculate below that these gender differences might tap a realization among women that the "costs" of adopting the sick role for pregnancy can outweigh the "benefits."

Endorsement of the Excuse component is directly associated with the variable Woman, and there is a Woman $x$ SES interaction. Women are less likely than men to think that pregnant women should be excused from other role responsibilities. Furthermore, women of higher socioeconomic status are even less likely to hold this expectation. We suspect that, in general, women tend to recognize the irreconcilability of multiple roles and the difficulty of being excused from them. Such an explanation is consistent with investigations describing only limited change in women's role within the family in the face of changing attitudes toward women's role outside the home (Morgan \& Walker, 1983; Ross, 1987). In addition, because of variations in job and career orientations and investments across socioeconomic groups, higher-status 
women probably have even more difficulty than lower-status women in abdicating such responsibilities. Women, especially women of high SES, have more to lose if women are expected to be excused from other role responsibilities when they are pregnant.

Among the four sick role components, No Fault is the only one not related to gender. Instead, support for the No Fault expectation is significantly stronger among younger and middle-aged respondents and among those of lower socioeconomic status. There is an interaction effect of age and SES, however, such that socioeconomic status does not have the inverse effect among the younger respondents that it has among middle-aged and older respondents. Because the No Fault items are linked to sick leave, the pattern of findings reflects the social context within the work force. Low-status people might be more supportive of the notion of sick leave for pregnancy, since they are the people who, because their jobs require relatively less skill, are most easily replaced if they have to be absent from work for a prolonged period. They also are less able to pay for expensive in-home care for newborns in order to quickly return to work. It is not surprising that younger and middle-aged respondents who are still in their childbearing years are most supportive of sick leave for pregnancies since they are the potential beneficiaries. The interaction effect suggests that support for this expectation is strong in this age group across all levels of socioeconomic status.

Endorsement of the Get Well dimension is related to three of the independent variables, including gender. Middle-aged and older respondents were more likely than younger respondents to expect pregnant women to want to return quickly to normal role responsibilities. Younger people, of course, are the ones having most of the babies. Women also are more likely than men to hold this expectation, and the expectation is positively related to socioeconomic status. Again, this might reflect a recognition by women, especially high SES women, that they must balance multiple roles in order to protect investments they have made in achieved statuses including careers. Furthermore, given the typical division of labor in current households, it might reflect a blunt realization by women that they simply must resume household responsibilities as soon as possible after birth.

The final component of the sick role, Care, concerns seeking care and cooperating with care givers. As revealed in Table 1 , endorsement among our respondents is more widespread for this expectation than for any of the others. Among whites, the expectation decreases with decreases in socioeconomic status. In the United States today, the availability of prenatal care is associated with socioeconomic status. Although Medicaid assistance does reimburse women for such care, the complexities of documenting the need for aid throughout a pregnancy is a barrier to adequate prenatal care (St. John \& Winston, 1989), and the parameters for Medicaid service exclude a segment of medically indigent women. We suspect this barrier is manifest in our data indicating that, among whites, support for the Care expectation is weaker among respondents of lower SES.

For Care, as for Excuse and Get Well, we again found gender differences. Women score significantly higher on this expectation than do men. The difference between men and women on this component has important implications, given the argument by St. John and Winston (1989) that "social support," or encouragement from others, might be a significant factor leading women to seek adequate care during pregnancy. The effect of gender on Care in our analysis implies that for some couples the expectation that pregnant women should seek care might be more strongly held by the women than by the men, indicating that many pregnant women are not receiving the kind of support that would facilitate their seeking adequate care. System barriers such as transportation problems, complexities of managing child care, etc. that require absence from the home and/or work probably enter into family decisions about resource allocation. In order for a woman to get 
care, decisions must be made within the family to expend resources of time, energy, and money.

\section{CONCLUSION}

We have conceptualized the "role" of pregnancy as the expectations society holds for pregnant women, rather than as the behavior of pregnant women or the expectations pregnant women hold for themselves. With this orientation, our analysis leads us to agree at least partially with McKinlay's (1972) assertion that the role of pregnancy is ill-defined and ambiguous. We find that various expectations are not shared equally across all categories of gender, age, socioeconomic status, and race. Furthermore, there is little consistency in the effects of these sociodemographic variables across the various role components we have analyzed, and some significant interaction effects appear but not for all components.

We must disagree, however, with McKinlay's claim that normal pregnancy "cannot be viewed in terms of any of the four expectations thought to be associated with the sick role" $(1972, p$. 570). An overwhelming majority of the respondents in our sample held expectations for pregnant women that are analogous to expectations for sick people. This finding should not be surprising given the medicalization of childbirth in our society (Leavitt, 1986). As long as pregnant women are expected to receive care in the same settings and from the same practitioners as sick people, we might expect the public to view being pregnant as analogous to being sick. In this current context, Parsons's analysis of the sick role becomes a useful heuristic tool for studying the expectations surrounding pregnancy, and each of the four sick role components captures important issues.

Throughout the analysis we found that women seemed more likely to recognize the costs and limitations of the sick role as a response to pregnancy, even though they were more likely than men to expect pregnant women to seek care. In our opinion, the vulnerability associated with the sick role should be addressed as a possible barrier to women's obtaining adequate health care during pregnancy. One possible policy alternative is the development of health care programs for pregnant women that do not require them to assume the sick role and become "patients." A model of such care has begun to emerge and involves primarily nurse midwives and other nurse practitioners. According to this model, the pregnant woman participates in her own care by becoming familiar with her body processes and monitoring them in conjunction with the health care giver. Decisions concerning life-style practices rest with the women in conjunction with the health care givers. Typical medical routines of concealing information from the patient and expecting unquestioned compliance are not necessary and, in fact, are inappropriate. The necessity of placing alternative care programs geographically separate from the traditional care locations, such as hospitals, has been advocated to weaken the link between pathology and pregnancy (DeVries, 1980; Ernst, 1982; Lubic \& Ernst, 1978).

To be in need of care is to be enmeshed with other issues that make pregnant women potentially vulnerable. Efforts to promote adequate health care during pregnancy need to address these larger social issues.

\section{REFERENCES}

Arluke, A., Kennedy, L., \& Kessler, R. (1979). Reexamining the sick-role concept: An empirical assessment. Journal of Health and Social Behavior, 20, 30-36.

Arms, S. (1975). Immaculate deception. New York: Bantam Books.

Arpad, S. (Ed.). (1984). Sam Curd's diary: The diary of a true woman. Athens, $\mathrm{OH}$ : Ohio University Press.

Blackwell, B. (1967). Upper middle class adult expectations about entering the sick role for physical and psychiatric dysfunctions. Journal of Health and Social Behavior, 8, 83-95. Bromberg, J. (1981). Having a baby: A story 
essay. In S. Romalis (Ed.), Childbirth: Alternatives to medical control. Austin: University of Texas Press.

Brown, A. (Ed.). (1988). Prenatal care: Reaching mothers, reaching infants. Washington, DC: National Academy Press.

Children's Defense Fund. (1987). Maternal and child health databook. Washington, DC: Author.

Collver, A., \& Have, R. (1974). Factors influencing the use of maternal health services. Social Science and Medicine, 8, 293-308.

DeLee, J. (1920). The prophylactic forceps operations. American Journal of Obstetrics and Gynecology, 1, 34-44.

DeVries, R. G. (1980). The alternative birth center: Option or cooptation? Women's Health, 5(3), 47-60.

Ehrenreich, B., \& English, D. (1978). For her own good: 150 years of the experts' advice to women. Garden City, NY: Anchor Press/ Doubleday.

Ernst, K. (1982). CBCN News, 1(2\&3), 5.

Hart, N. (1977). Parenthood and patienthood: A dialectical autobiography. In A. Davis \& G. Horobin (Eds.), Medical encounters: The experience of illness and treatment. New York: St. Martin's Press.

Hern, W. (1975). The illness parameters of pregnancy. Social Science and Medicine, 9, 365-372.

Joyce, K., Diffenbacher, G., Greene, J., \& Sorokin, Y. (1983). Internal and external barriers to obtaining prenatal care. Social Work Health Care, 9, 89-96.

Kaliszer, M., \& Kidd, M. (1981). Some factors affecting attendance at ante-natal clinics. Social Science and Medicine, 15(d), 421-424.

Kassebaum, G., \& Baumann, B. (1965). Dimensions of the sick role in chronic illness. Journal of Health and Social Behavior, 6, 16-27.

Kitzinger, S. (1985). The sexuality of birth. In S. Kitzinger (Ed.), Women's experience of sex. New York: Penguin Books.

Leavitt, J. (1986). Brought to bed: Childbearing in America, 1750 to 1959. New York: Oxford University Press.

Lubic, R. W., \& Ernst, E. K. M. (1978). The child bearing center: An alternative to conventional care. Nursing Outlook, 26(2), 754760.

McKinlay, J. (1972). The sick role-Illness and pregnancy. Social Science and Medicine, 6, 561-572.

Mechanic, D. (1962). The concept of illness behavior. Journal of Chronic Diseases, 15, 189-194.

Morgan, C., \& Walker, A. (1983). Predicting sex role attitudes. Social Psychology Quarterly, 46, 148-151.

Nathanson, C. (1975). Illness and the feminine role: A theoretical review. Social Science and Medicine, 9, 57-62.

Oakley, A. (1980). Women confined: Towards a sociology of childbirth. New York: Schocken Books.

Oakley, A. (1984). The captured womb. New York: Basil Blackwell.

Parsons, T. (1951). The social system. New York: The Free Press.

Parsons, T. (1964). Definitions of health and illness in the light of American values and social structure. In T. Parsons (Ed.), Social structure and personality (pp. 257-291). New York: The Free Press of Glencoe.

Parsons, T. (1975). The sick role and the role of the physician reconsidered. Milbank Memorial Fund Quarterly, 53, 257-278.

Polland, M., Ager, J., \& Olson, J. (1987). Barriers to receiving adequate prenatal care. American Journal of Obstetrics Gynecology, 157(2), 297-303.

Romalis, S. (1981). Childbirth: Alternatives to medical control. Austin: University of Texas Press.

Rosengren, W. (1961). Social sources of pregnancy as illness or normality. Social Forces, 39, 260-267.

Rosengren, W. (1962a). The sick role during pregnancy: A note on research in progress. 
Journal of Health and Social Behavior, 3, 213-218.

Rosengren, W. (1962b). Social instability and attitudes toward pregnancy as a social role. Social Problems, 9, 371-378.

Ross, C. (1987). The division of labor at home. Social Forces, 65, 816-833.

Rothman, B.(1982). In labor: Women and power in the birthplace. New York: W. W. Norton \& Company.

Rubin, R. (1967a). Attainment of the maternal role. Part I. Nursing Research, 16, 342-346.

Rubin, R. (1967b). Attainment of the maternal role. Part II. Nursing Research, 16, 342-346.

Ryan, G., Sweeney, P., \& Solola, A. (1980). Prenatal care and pregnancy outcome. American Journal of Obstetrics Gynecology, 137, 876-881.

St. John, C., \& Winston, T. (1989). The effect of social support on prenatal care. Journal of Applied Behavioral Science, 25, 79-98.
Shaw, N. (1974). Forced labor: Maternity care in the United States. New York: Pergamon Press.

Twaddle, A. (1969). Health decisions and sick role variations: An exploration. Journal of Health and Social Behavior, 10, 105-115.

Twaddle, A., \& Hessler, R. (1977). The sickness career. In A.Twaddle \& R. Hessler (Eds.), A sociology of health. St. Louis: C.V. Mosby. van Gennep, A. (1960). Rites of passage. Chicago: University of Chicago Press. (Original work published in French in 1909)

Watkins, E. (1978). Low-income Negro mothers-Their decision to seek prenatal care. American Journal of Public Health, 58, 655667.

Williams, M., Joy, L., Travis, L., Gotowiec, A., Blum-Steele, M., Aiken, L., Painter, S., \& Davidson, S. (1987). Transition to motherhood: A longitudinal study. Infant Mental Health Journal, 8, 251-256. 